\title{
Anthologie de la littérature érotique du Moyen Âge. Textes édités, traduits et commentés par $C$. PIERREVILLE
}

\section{Maria Colombo Timelli}

\section{(2) OpenEdition}

1 Journals

\section{Édition électronique}

URL : https://journals.openedition.org/studifrancesi/32548

DOI : 10.4000/studifrancesi.32548

ISSN : 2427-5856

Éditeur

Rosenberg \& Sellier

\section{Édition imprimée}

Date de publication : 1 août 2020

Pagination : 373

ISSN : 0039-2944

\section{Référence électronique}

Maria Colombo Timelli, «Anthologie de la littérature érotique du Moyen Âge. Textes édités, traduits et commentés par C. PIERREVILLE », Studi Francesi [En ligne], 191 (LXIV | II) | 2020, mis en ligne le 01 septembre 2020, consulté le 17 septembre 2021. URL : http://journals.openedition.org/studifrancesi/ 32548 ; DOI : https://doi.org/10.4000/studifrancesi.32548

Ce document a été généré automatiquement le 17 septembre 2021.

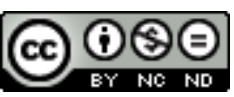

Studi Francesi è distribuita con Licenza Creative Commons Attribuzione - Non commerciale - Non opere derivate 4.0 Internazionale. 


\title{
Anthologie de la littérature érotique du Moyen Âge. Textes édités, traduits et commentés par C. PIERREVILLE
}

\author{
Maria Colombo Timelli
}

\section{RÉFÉRENCE}

Anthologie de la littérature érotique du Moyen Âge. Textes édités, traduits et commentés par C. PIERREVILLE, Paris, Honoré Champion, 2019, «Champion Classiques - Moyen Âge», 485 pp.

1 Vingt-six pièces «érotiques» en langue d'oïl et en langue d'oc, composées du XII ${ }^{\mathrm{e}} a \mathrm{Xv}^{\mathrm{e}}$ siècle, trouvent grâce à C.P. une nouvelle édition accompagnée de traduction en français moderne. L'Introduction, qui occupe plus de 70 pages, s'ouvre sur une réflexion approfondie sur l'érotisme: cette notion, qui risque de paraitre facilement définissable voire banale au lecteur moyen, s'avère en réalité complexe et d'autant plus compliquée dès qu'on se demande ce qui pouvait être perçu comme «érotique» au Moyen Âge. C.P. s'appuie d'abord sur les choix opérés par les nombreux éditeurs d'anthologies comparables, dont elle prend les distances pour en arriver à une définition clairement énoncée sur la base du TLFi et sur laquelle elle a fondé ses propres choix: «[érotisme] se réfère selon les emplois à une tendance vive à l'amour, un goût pour les plaisirs de la chair et désigne, par métonymie, ce qui a pour thème, pour sujet ou pour inspiration, l'amour charnel» (p. 18, je modifie la ponctuation). D'autres aspects sont aussi pris en compte dans ces riches pages liminaires: on rappellera entre autres la discussion du rapport avec la pornographie et l'obscénité ou la question du «rire». Surtout, est prise en compte l'évolution des mentalités à l'égard de la sexualité telle qu'elle se manifeste sur la longue diachronie dans les textes non littéraires: traités de médecine, actes de procès, sermons, pénitenciels; ce qui permet de mesurer la richesse d'une réflexion bien connue par les historiens spécialistes, beaucoup moins par les littéraires et par les 
lecteurs d'aujourd'hui. Une deuxième partie est consacrée, comme il se doit, aux textes-souvent anonymes - et auteurs-hommes pour la plupart, mais quelques femmes apparaissent-représentés dans ce florilège. Les Principes de constitution de l'ouvrage sont clairement précisés pp. 71-76; on retiendra en particulier l'exclusion des textes en latin et le choix d'une présentation en quelque sorte thématique (ni chronologique, ni générique, donc), qui regroupe les extraits sur la base d'un «imaginaire érotique» qui serait inaltérable dans le temps. Loin de se baser sur les éditions existantes, C.P. donne ici une nouvelle édition de chaque texte; quelques pages de présentation surtout littéraire indiquent aussi sa tradition manuscrite et les critères suivis dans le choix du témoin de base; à ce propos, un seul petit regret: on aurait aimé trouver, avec la cote des manuscrits, l'époque de leur facture, ce qui aurait donné une idée de la diffusion et de la fortune éventuelle des textes tout au long du Moyen Âge.

2 Une liste exhaustive des œuvres contenues dans ces pages serait fastidieuse, le fichier pdf de la Table des matières étant par ailleurs disponible sur le site de Champion; soulignons plutôt la variété poursuivie par C.P.: variété linguistique (langue d'oc et langue d'oïl, comme on l'a dit), variété générique (poésie lyrique, roman, fabliaux, correspondance, théâtre), fourchette chronologique longue ( $\mathrm{XII}^{\mathrm{e}}-\mathrm{XV}^{\mathrm{e}}$ siècle). Rappelons aussi l'insertion d'une série de reproductions en couleurs: miniatures et décorations marginales en rapport avec l'érotisme, certes, mais pas nécessairement avec les textes édités ici. La bibliographie (pp.431-475) est raisonnée; une première section se rapporte aux textes édités, divisés ici par genres, et comprend tant les éditions des textes que la bibliographie critique; elle est suivie par des sections de bibliographie secondaire: études sur la Sexualité du Moyen Âge à nos jours et sur Érotisme, pornographie, obscénité; suivent: la liste des anthologies déjà disponibles et les Dictionnaires de l'érotisme, de la pornographie ou de la sexualité, parmi lesquels l'on trouvera, pour la langue médiévale, le Dictionnaire érotique. Ancien français, Moyen Français, Renaissance de Rose M. Bidler (Montréal, 2002). Les toutes dernières pages (477-480) proposent un Petit lexique des termes érotiques, avec gloses et renvois aux textes. 